Review

\title{
Clinical implications of HLA locus mismatching in unrelated donor hematopoietic cell transplantation: a meta-analysis
}

\author{
Ruxiu Tie ${ }^{1, *}$, Tiansong Zhang ${ }^{2, *}$, Bo Yang ${ }^{3, *}$, Huarui Fu' ${ }^{1}$, Biqing Han ${ }^{1}$, Jian $\mathbf{Y u}^{1}$, \\ Yamin $\operatorname{Tan}^{1}$ and He Huang ${ }^{1}$ \\ ${ }^{1}$ Bone Marrow Transplantation Center, The First Affiliated Hospital, College of Medicine, Zhejiang University, Hangzhou, \\ China \\ ${ }^{2}$ Department of Traditional Chinese Medicine, Jing'an District Central Hospital, Shanghai, China \\ ${ }^{3}$ School of Public Health, Wenzhou Medical University, Wenzhou, China \\ * These authors contributed equally to the work \\ Correspondence to: He Huang, email: huanghe@zju.edu.cn
}

Keywords: HLA locus; hematopoietic cell transplantation; unrelated donor; meta-analysis

Received: July 28, $2016 \quad$ Accepted: January 26, $2017 \quad$ Published: February 11, 2017

Copyright: Tie et al. This is an open-access article distributed under the terms of the Creative Commons Attribution License (CC-BY), which permits unrestricted use, distribution, and reproduction in any medium, provided the original author and source are credited.

\section{ABSTRACT}

It remains controversial that the impacts of individual HLA locus mismatches on clinical outcomes of patients receiving unrelated-donor hematopoietic cell transplantation (HCT), as compared to HLA allele matched controls. We conducted a meta-analysis to address these issues. Four databases (PubMed, Embase, Web of Science and the Cochrane Library) were searched to select eligible studies. All donor-recipient pairs were high-resolution typing for HLA-A, -B, -C, -DRB1, DQB1 and DPB1 loci. Multivariate-adjusted hazard ratios (HRs) were extracted and pooled using a random-effects model. A total of 36 studies were included, with 100,072 patients receiving HCT. Surprisingly, we found that HLA-DQB1 locus mismatches had no significantly increased risk of multiple outcomes including acute and chronic graftversus-host disease (GVHD), overall mortality and disease relapse (HR, 1.07; $P=$ $.153 ; \mathrm{HR}, 1.07 ; P=.271 ; \mathrm{HR}, 1.09 ; P=.230 ; \mathrm{HR}, 1.07 ; P=.142$ and $\mathrm{HR}, 1.02 ; P=$ .806 , respectively). Mismatched HLA-DPB1 was significantly associated with a reduced risk of disease relapse $(H R, 0.74 ; P<.001)$ but not with increased risks of transplantrelated mortality (TRM) and overall mortality $\left(H R, 1.09 ; P=.591 ; I^{2}=74.2 \%\right.$ and $H R, 1.03 ; P=.460$, respectively). In conclusion, HLA-DQB1 locus mismatches is a permissive mismatching. HLA-DPB1 locus mismatches significantly protect against leukemia relapse. Refining effects of individual HLA locus mismatches contributes to predicting prognosis of patients receiving unrelated donor HCT.

\section{INTRODUCTION}

During the past 36 years, unrelated donor HCT has already become one of the most effective but complex therapy for selected patients with hematologic malignancies or certain life-threatening nonmalignant disorders $[1,2]$. However, the clinical application of the HCT is limited by leukemia relapse [3] and lifethreatening complications, such as graft-versus-host disease (GVHD) [4, 5], infection [6-8], conditioning regimen-related toxicities [9-11], and transplant-associated thrombotic microangiopathy (TMA) [12-14] as well, which are more common in patients receiving HLA locus mismatched grafts. In clinical practice, it is increasingly difficult to identify a HLA locus completely matched donor in the presence of highly polymorphic HLA alleles. The most loci are the HLA class I (A, B and C) and the class II (DRB1, DQB1 and DPB1) molecules [15].

A large number of studies assessed the impact of individual HLA mismatches on multiple clinical outcomes [16-51]. For a given end point, the risk of a specific HLA locus mismatches was generally inconsistent or even contradictory across studies. These discrepancies make it difficult to figure out which mismatched HLA loci contribute mainly to the incidence and severity of GVHD, TRM and mortality, and which HLA locus mismatches has minimal impact on outcomes. Despite there are several guidelines published, evidence-based 
recommends have been absent so far [52-55]. Most recently, a published meta-analysis assess the impact of HLA-DPB1 allele mismatches on overall survival of patients receiving unrelated-donor HCT [56]. Other important end points were not mentioned, and many studies with large populations were not included in the review. Additionally, the analysis of individual HLA locus mismatches at the antigen level was not performed in the absence of sufficient data. As such, we undertake the meta-analysis in an effort to identify potential permissive HLA locus mismatches and candidate markers for protecting against primary disease relapse by means of systematically and comprehensively assessing the impacts of both individual HLA locus mismatches and number of HLA locus mismatches on multiple outcomes, which is of great benefit for ascertaining acceptable HLA minimal mismatched grafts and for predicting prognosis of patients after unrelated-donor HCT.

\section{RESULTS}

\section{Study and patient characteristics}

The flow diagram of study search and selection was illustrated in Figure 1. The search strategy was showed in Supplementary Table 1. A total of 36 studies were included [16-51], of which, 15 studies analyzed 6 HLA loci $[17,18,23,24,26,28,30,31,35,42,44-47,50], 8$ researches mentioned 5 HLA loci [16, 19-22, 27, 29, 38], and 14 studies investigated 4 HLA loci [25, 32-34, 37, 39-41, 43, 44, 48, 49, 51] (Table 1). Study characteristics were showed in Supplementary Table 2, all of the included studies were at low risk of bias. Polymorphism and matching likelihood at individual HLA loci were showed in Figure 2. Class I HLA alleles are more polymorphic than Class II HLA alleles, which was also seen in terms of protein diversity. The highest mismatch likelihood was seen in patients with HLA-DPB1 and -C locus mismatches.

\section{Acute GVHD}

With respect to recipients with $\mathrm{HLA}-\mathrm{A},-\mathrm{B},-\mathrm{C}$, -DRB1, or -DPB1 locus mismatches, the risk of acute GVHD (III-IV) was significantly higher, with hazard ratios of $1.40(95 \% \mathrm{CI}, 1.28$ to $1.54 ; P<.001), 1.42(95 \%$ CI, 1.24 to $1.62 ; P<.001), 1.50$ (95\% CI, 1.33 to $1.69 ; P$ $\left.<.001 ; \mathrm{I}^{2}=58.5 \%\right), 1.26(95 \% \mathrm{CI}, 1.14$ to $1.40 ; P<.001)$ and 1.24 (95\% CI, 1.16 to 1.33$)$, respectively, as compared to controls (Figure 3). However, HLA-DQB1 mismatches did not have a significant impact on acute GVHD (III-IV) (HR, $1.07 ; 95 \% \mathrm{CI}, 0.95$ to $1.20 ; P=.271$ ) (Figure 3 ). The effect of individual HLA mismatches was replicated for acute GVHD (II-IV), with substantial heterogeneity in the analysis of HLA-DPB1 locus $\left(\mathrm{I}^{2}=63.9 \%\right)$ (Figure 3 ).

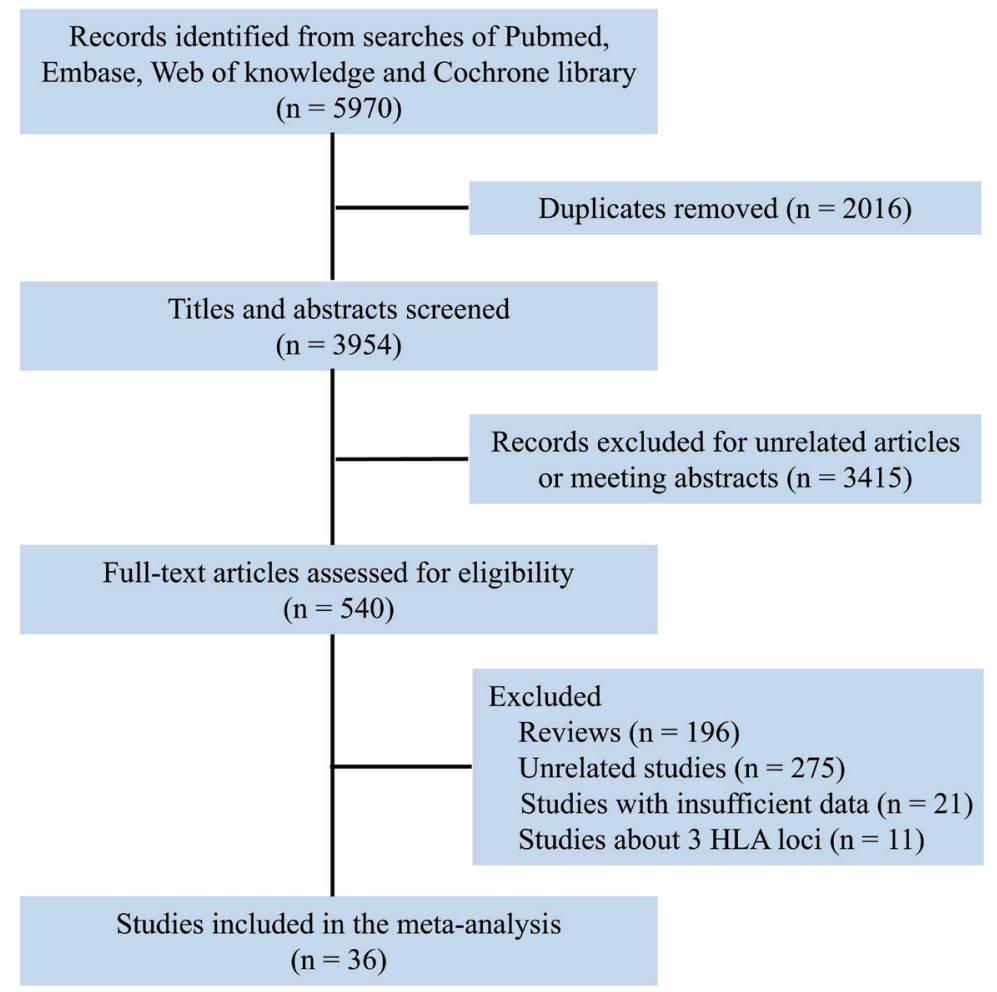

Figure 1: Flow chart for selection of studies. 
Secondly, we investigated the impact of nonpermissive HLA-DPB1 mismatches on aGVHD (Figure 4). Among patients with 10/10 HLA matching, nonpermissive HLADPB1 mismatches were associated with a significantly increased risk of acute GVHD (III-IV) $(P<.001)$, and had a trend of slight increasing risk of acute GVHD (IIIV) $(P=.101)$. Conversely, matched HLA-DPB1 was significantly associated with decreased incidence of acute
GVHD (II-IV) $(P<.001)$ and GVHD (III-IV) $(P=.023)$. In the $9 / 10$ HLA matching population, both nonpermissive mismatched and matched HLA-DPB1 did not have statistically significant impacts on grade II-IV or III-IV acute GVHD (all $P>.05$ ). Thirdly, we assessed the risks of aGVHD for number of HLA locus mismatches (Figure 5). Compared with recipients with $8 / 8$ HLA matching, those with $7 / 8$ HLA matching had a higher risk of acute

A

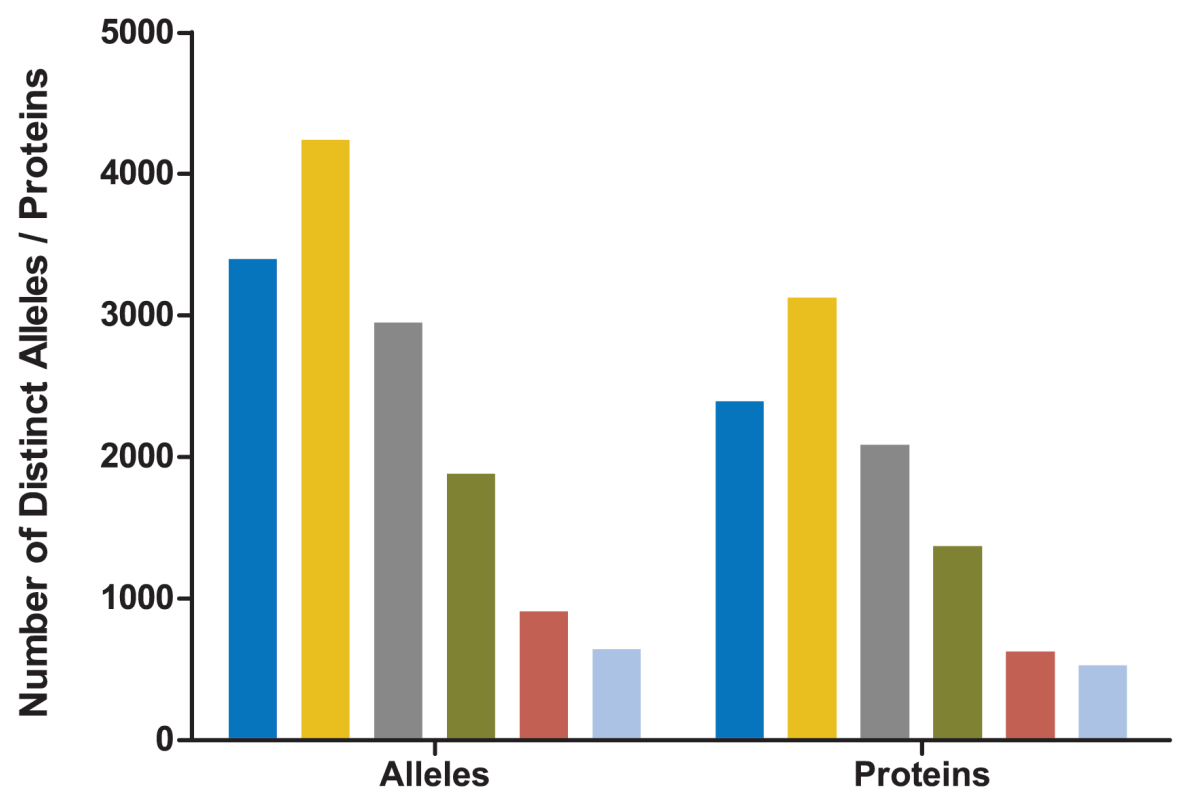

HLA-A

HLA-B

HLA-C

HLA-DRB1

HLA-DQB1

- HLA-DPB1

B

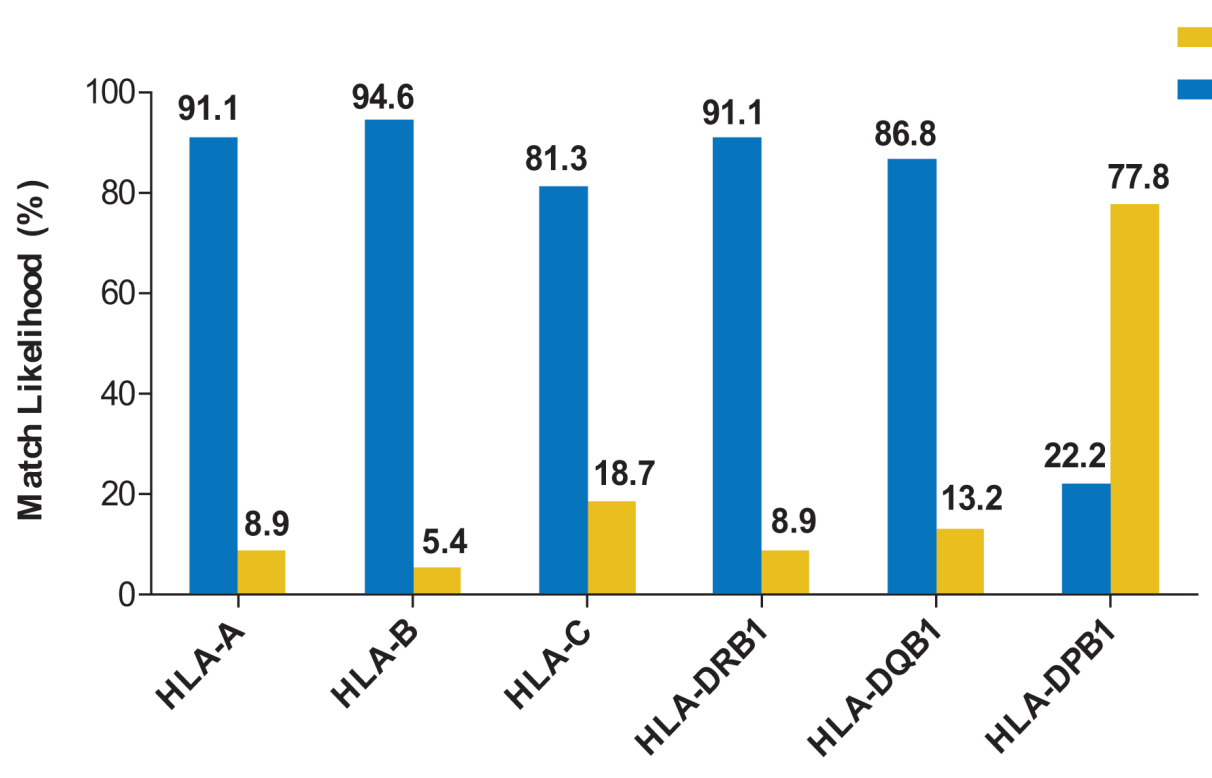

Figure 2: Polymorphism and match likelihood for individual HLA loci. (A) allelic polymorphism and protein diversity for individual HLA loci, data were taken from http://www.ebi.ac.uk/imgt/hla/stats.html; accessed April, 2016. (B) match and mismatch likelihood of individual HLA loci. 
Table 1: Patient, donor and transplantation characteristics according to number of HLA locus.

\begin{tabular}{|c|c|c|c|c|}
\hline Characteristic and stratum & Total & HLA 4 loci & HLA 5 loci & HLA 6 loci \\
\hline Number of studies & 36 & 14 & 8 & 15 \\
\hline Patients, no. (\%) & $100,072(100)$ & $47,837(40.9)$ & $10,932(12.1)$ & $41,303(47.0)$ \\
\hline Patient age, median (range), $y$ & $40.5(0-81)$ & $40.5(0-81)$ & $39.5(0-79)$ & $38.5(0-77)$ \\
\hline Donor age, median (range), y & $41(3-79)$ & $39(3-75)$ & $48.5(18-79)$ & $35(3-67)$ \\
\hline \multicolumn{5}{|l|}{ Disease at HCT, no. (\%) } \\
\hline Acute lymphoblastic leukemia & $22,210(22.2)$ & $10,543(22.0)$ & $1,907(17.4)$ & $9,760(23.6)$ \\
\hline Acute myeloblastic leukemia & $37,115(37.1)$ & $21,996(46.0)$ & $2,681(24.5)$ & $12,438(30.1)$ \\
\hline Chronic myeloid leukemia & $21,027(21.0)$ & $8,514(17.8)$ & $3,704(33.9)$ & $8,809(21.3)$ \\
\hline Myelodysplastic syndrome & $10,654(10.6)$ & $6,010(12.6)$ & $994(9.1)$ & $3,650(8.8)$ \\
\hline Lymphoid malignancy & $2,289(2.3)$ & $43(0.1)$ & $652(6.0)$ & $1,594(3.9)$ \\
\hline Aplastic anemia & $881(0.9)$ & $275(0.6)$ & $112(1.0)$ & $494(1.2)$ \\
\hline Multiple myeloma & $519(0.5)$ & $2(<0.1)$ & $280(2.6)$ & $237(0.6)$ \\
\hline Others & $3,491(3.5)$ & $454(0.9)$ & $602(5.5)$ & $2,435(5.9)$ \\
\hline Missing & $1,886(1.9)$ & 0 & 0 & $1,886(4.6)$ \\
\hline \multicolumn{5}{|l|}{ Graft source, no. (\%) } \\
\hline Bone marrow & $69,941(69.9)$ & $26,909(56.3)$ & $7,305(66.8)$ & $35,727(86.5)$ \\
\hline Peripheral blood & $29,797(29.8)$ & $20,928(43.7)$ & $3,483(31.9)$ & $5,386(13.0)$ \\
\hline Missing & $334(0.3)$ & 0 & $144(1.3)$ & $190(0.5)$ \\
\hline \multicolumn{5}{|l|}{ Disease status at HCT, no. (\%) } \\
\hline Standard & $41,857(41.8)$ & $24,523(51.3)$ & $3,572(32.7)$ & $13,762(33.3)$ \\
\hline High (intermediate and advanced) & $47,092(47.1)$ & $21,906(45.8)$ & $6,647(60.8)$ & $18,539(44.9)$ \\
\hline Missing & $11,123(11.1)$ & $1,408(2.9)$ & $713(6.5)$ & $9,002(21.8)$ \\
\hline \multicolumn{5}{|c|}{ Performance status prior to HCT, no. (\%) } \\
\hline$<90$ & $14,081(14.0)$ & $12,540(26.2)$ & 0 & $1,541(3.7)$ \\
\hline $90-100$ & $31,001(31.0)$ & $26,755(55.9)$ & 0 & $4,246(10.3)$ \\
\hline Missing & $54,990(55.0)$ & $8,542(17.9)$ & $10,932(100)$ & $35,516(86.0)$ \\
\hline \multicolumn{5}{|l|}{ Donor/recipient gender match, no. (\%) } \\
\hline Male to male & $30,547(30.5)$ & $12,462(26.0)$ & $3,990(36.5)$ & $14,095(34.1)$ \\
\hline Male to female & $17,655(17.6)$ & $7,948(16.6)$ & $2,330(21.3)$ & $7,377(17.9)$ \\
\hline Female to male & $14,715(14.7)$ & $5,839(12.2)$ & $1,809(16.5)$ & $7,067(17.1)$ \\
\hline Female to female & $14,399(14.4)$ & $5,868(12.3)$ & $1,800(16.5)$ & $6,731(16.3)$ \\
\hline Missing & $22,756(22.7)$ & $15,720(32.9)$ & $1,003(9.2)$ & $6,033(14.6)$ \\
\hline \multicolumn{5}{|c|}{ Donor/recipient CMV serostatus, no. (\%) } \\
\hline Negative/negative; -/- & $15,474(15.5)$ & $11,192(23.4)$ & $105(1.0)$ & $4,177(10.1)$ \\
\hline Negative/positive; -/+ & $14,736(14.7)$ & $11,622(24.3)$ & $74(0.7)$ & $3,040(7.4)$ \\
\hline Positive/positive; $+/+$ & $9,265(9.3)$ & $6,726(14.0)$ & $68(0.6)$ & $2,471(6.0)$ \\
\hline Positive/negative; +/- & $7,840(7.8)$ & $5,343(11.2)$ & $59(0.5)$ & $2,438(5.9)$ \\
\hline Missing & $52,757(52.7)$ & $12,954(27.1)$ & $10,626(97.2)$ & $29,177(70.6)$ \\
\hline \multicolumn{5}{|l|}{ Conditioning regimen, no. $(\%)$} \\
\hline Myeloablative & $76,240(76.2)$ & $38,240(79.9)$ & $8,248(75.4)$ & $29,752(72.0)$ \\
\hline Reduced intensity & $13,423(13.4)$ & $8,977(18.8)$ & $1,321(12.1)$ & $3,125(7.6)$ \\
\hline Missing & $10,409(10.4)$ & $620(1.3)$ & $1,363(12.5)$ & $8,426(20.4)$ \\
\hline \multicolumn{5}{|l|}{ Total body irradiation, no. (\%) } \\
\hline Yes & $36,000(36.0)$ & $16,793(35.1)$ & $1,780(16.3)$ & $17,427(42.2)$ \\
\hline No & $19,532(19.5)$ & $11,654(24.4)$ & $629(5.7)$ & $7,249(17.6)$ \\
\hline Missing & $44,540(44.5)$ & $19,390(40.5)$ & $8,523(78.0)$ & $16,627(40.2)$ \\
\hline \multicolumn{5}{|l|}{ GVHD prophylaxis, no. (\%) } \\
\hline Cyclosporine based & $29,584(29.6)$ & $15,675(32.8)$ & $2,986(27.3)$ & $10,923(26.4)$ \\
\hline Tacrolimus based & $34,734(34.7)$ & $23,205(48.5)$ & $210(1.9)$ & $11,319(27.4)$ \\
\hline Cyclosporine or tacrolimus based & $9,391(9.4)$ & $3,009(6.3)$ & 0 & $6,382(15.5)$ \\
\hline
\end{tabular}




\begin{tabular}{|l|c|c|c|c|}
\hline Others & $5,314(5.3)$ & $2,505(5.2)$ & $293(2.7)$ & $2,516(6.1)$ \\
\hline Missing & $21,049(21.0)$ & $3,443(7.2)$ & $7,443(68.1)$ & $10,163(24.6)$ \\
\hline T-cell depletion, no. (\%) & & & & \\
\hline Yes & $18,001(18.0)$ & $9,781(20.4)$ & $1,669(15.3)$ & $6,551(15.9)$ \\
\hline No & $67,387(67.3)$ & $26,258(54.9)$ & $8,864(81.1)$ & $32,265(78.1)$ \\
\hline Missing & $14,684(14.7)$ & $11,798(24.7)$ & $399(3.6)$ & $2,487(6.0)$ \\
\hline Year of transplantation & & & & \\
\hline & $1988-2012$ & $1988-2011$ & $1988-2010$ & $1988-2012$ \\
\hline
\end{tabular}

Abbreviations: HLA 4 Loci, HLA-A, -B, -C, and -DRB1 loci; HLA 5 Loci, HLA-A, -B, -C, DRB1 and -DQB1 loci; HLA 6 Loci, HLA-A, -B, -C, DRB1,-DQB1 and -DPB1 loci; HCT, hematopoietic cell transplantation; CMV, cytomegalovirus.

GVHD (II-IV) $(P<.001)$ and GVHD (III-IV) $(P<.001)$; those with $6 / 8$ matches had a higher risk of acute GVHD (II-IV) $(P<.001)$, and had a trend of increased incidence of acute GVHD (III-IV) $\left(P=.087 ; \mathrm{I}^{2}=78.0 \%\right)$. Only one study assessed the risk of the acute GVHD (II-IV) for $9 / 10$ HLA matches, compared with 10/10 matches $(P=.080)$.

\section{Chronic GVHD}

Patients with HLA-A locus mismatches had a higher risk of chronic GVHD (HR, 1.20; 95\% CI, 1.04 to 1.39; $P=.014 ; \mathrm{I}^{2}=50.4 \%$ ), compared with the control (Figure 3). Similarly, HLA-C locus mismatches slightly increased hazard of chronic GVHD with a borderline significance (HR, $1.13 ; 95 \% \mathrm{CI}, 1.01$ to $1.27 ; P=.047 ; \mathrm{I}^{2}=67.2 \%$ ) (Figure 3). However, mismatches at other HLA loci had no significant impact on chronic GVHD (all $P>.05$ ) (Figure 3). Secondly, both nonpermissive mismatched and matched HLA-DPB1 had no impact on the incidence of chronic GVHD (all $P>.05$ ) (Figure 3). Thirdly, compared with $8 / 8$ HLA matches, neither $7 / 8$ nor $6 / 8$ matches showed a higher risk of chronic GVHD $(P=.213$ and .522 , respectively).

\section{Neutrophil engraftment}

As shown in Figure 3, there was a trend of promoting neutrophil engraftment for recipients with individual HLA locus mismatches. Recipients with 7/8 HLA matching did not have an impact on neutrophil engfratment, compared with 8/8 matching (Figure 5).

\section{Relapse}

Mismatches at HLA-DPB1 locus was significantly associated with a decreased risk of primary disease relapse, compared with the control (HR, 0.74; 95\% CI, 0.68 to $0.80 ; P<.001$ ) (Figure 3). HLA-C locus mismatches has a trend of decreased relapse (HR, 0.84; $95 \% \mathrm{CI}, 0.69$ to $1.03 ; P=.102 ; \mathrm{I}^{2}=70.9 \%$ ) (Figure 3 ). Mismatches at HLA-A, -B, -DRB1 or DQB1 locus had no significant impact on disease relapse (all $P>.05$ )
(Figure 3). Secondly, in the population with 10/10 HLA matching, nonpermissive HLA-DPB1 mismatches had a trend of reduced disease relapse, $(P=.080)$ (Figure 4), whereas matched HLA-DPB1 had a higher risk of relapse $(P<.001)$ (Figure 4). That the impact of nonpermissive mismatched and matched HLA-DPB1 on disease relapse was not observed among the patients with 9/10 HLA matching ( $P=.900$ and $P=0.736$ ) (Figure 4). Thirdly, the impact on relapse was not observed in patients with $9 / 10,7 / 8$ and 6/8 HLA matching $(P=.516, .960$ and .360 , respectively) (Figure 5).

\section{TRM, mortality and DFS}

For recipients with mismatches at HLA-A, -B, -C -DRB1 or -DQB1 locus, the risk of TRM was significantly higher, as compared to controls, with hazard ratios of 1.47 (95\% CI, 1.26 to $1.71 ; P<.001), 1.54(95 \% \mathrm{CI}, 1.29$ to $1.83 ; P<.001), 1.35$ (95\% CI, 1.20 to $1.51 ; P<.001)$, $1.29(95 \% \mathrm{CI}, 1.02$ to $1.63 ; P=.033)$ and $1.30(95 \% \mathrm{CI}$, 1.01 to $1.67 ; P=.041$ ), respectively (Figure 3 ). Whereas, HLA-DPB1 mismatches had no significant impact on TRM $(P=.591)$ (Figure 3). With respect to mortality, intriguingly, similar results were observed for HLA-A, -B, -C, -DRB1 or DPB1 mismatches, with hazard ratios of 1.33 (95\% CI, 1.27 to $1.40 ; P<.001), 1.35$ (95\% CI, 1.21 to $1.50 ; P<.001), 1.23$ (95\% CI, 1.17 to $1.29 ; P$ $<.001), 1.19$ (95\% CI, 1.07 to $1.32 ; P=.033)$ and 1.03 ( $95 \%$ CI, 0.97 to $1.09 ; P=.460$ ), respectively (Figure 3 ). Whereas HLA-DQB1 locus mismatches had no significant impact on mortality $(P=.460)$, which is inconsistent with it for TRM (Figure 3). These data demonstrated that the pooled point estimates of class I HLA loci were prone to be greater than those of class II HLA loci, with respect to TRM and mortality. Additionally, the effect of mismatches at HLA-A, -B, -C, -DRB1 or -DQB1 locus was replicated for DFS, with few studies investigating this end point (Figure 3).

Secondly, we investigated the impact of nonpermissive HLA-DPB1 mismatches on TRM and mortality (Figure 4). In the 10/10 HLA matching population, the risk of TRM and mortality was significantly greater for nonpermissive HLA-DPB1 


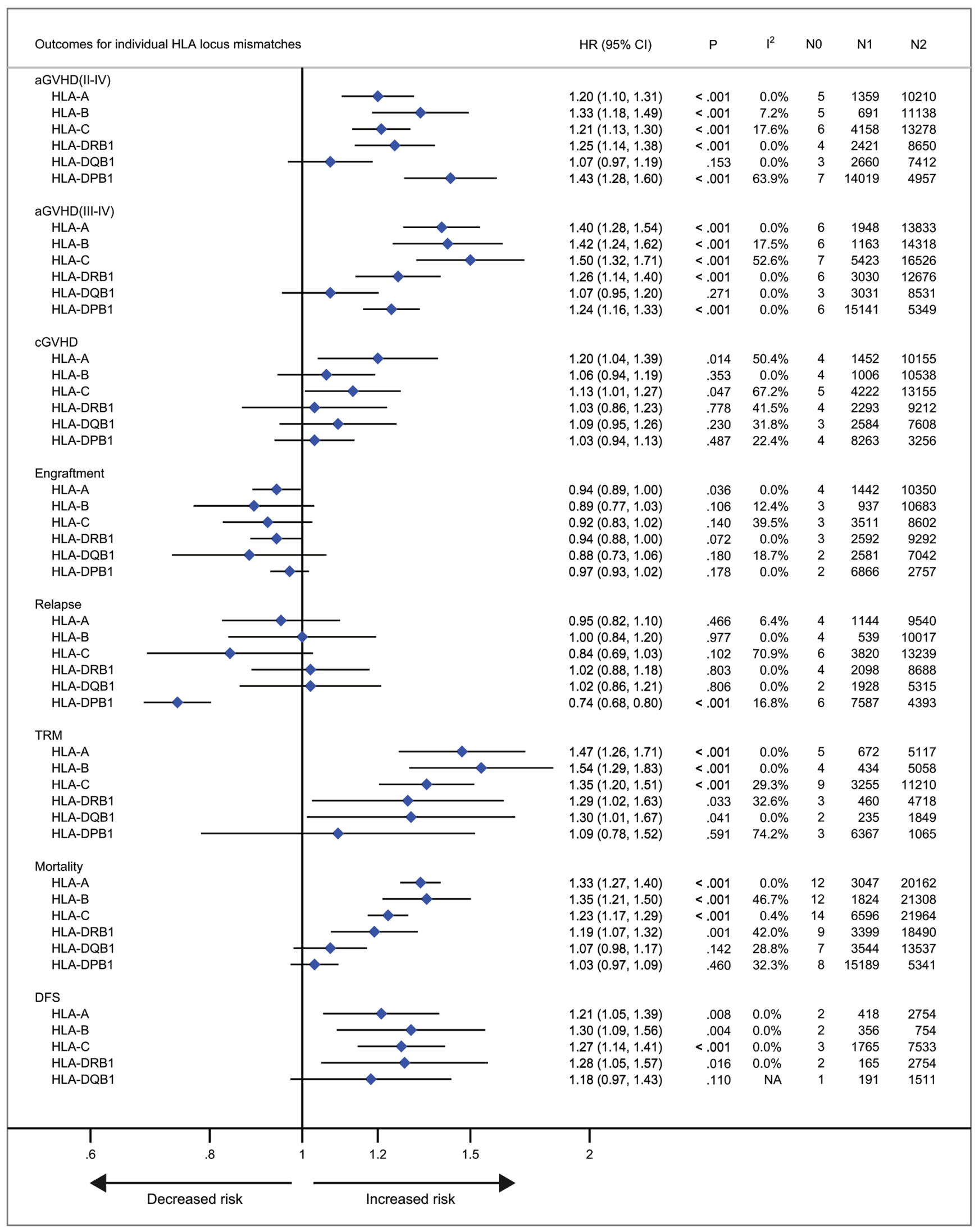

Figure 3: Individual HLA locus mismatches versus corresponding controls. Pooled hazard ratios (HRs) and $95 \%$ CIs for posttransplantation end points. N0, number of studies; N1, number of patients with a specific HLA locus mismatches; N2, number of patients as corresponding controls; NA, not available. 
mismatches $(P<.001$ and $P<.001$, respectively). In contrast, matched HLA-DPB1 had a marginally significant effect of protecting against TRM $(P=.029)$. But for mortality, the impact of matched HLA-DPB1 was not identified $(P=.986)$. Among the $9 / 10$ HLA matching patients, matched HLA-DPB1 did not result in a decreased risk of TRM and mortality $(P=.313$ and $P=.259$, respectively); similarly, the impact on TRM was replicated in patients with nonpermissive HLA-DPB1 mismatches $(P$ $=.144$ ), but increasing risk of mortality was observed for the mismatches, with a borderline significance (HR, 1.10; 95\% CI, 1.01 to $1.20 ; P=.033$ ).

Thirdly, as shown in Figure 5, compared with 10/10 matching, there was a significantly increased risk of TRM and mortality for both 9/10 and 8/10 HLA mismatches. Furthermore, the pooled point estimate of $8 / 10$ HLA mismatches was greater than it of $9 / 10$ mismatches. The findings were replicated in both $7 / 8$ and 6/8 HLA mismatches, compared with 8/8 HLA matching. And similar results were observed in terms of DFS.

\section{Stratified analyses}

Stratified analysis was showed in Tables S3-5 according to combinations of HLA allele or antigen mismatches. Only one study analyzed 1 or 2 antigen mismatches so that the pooled analysis could not be performed [38].

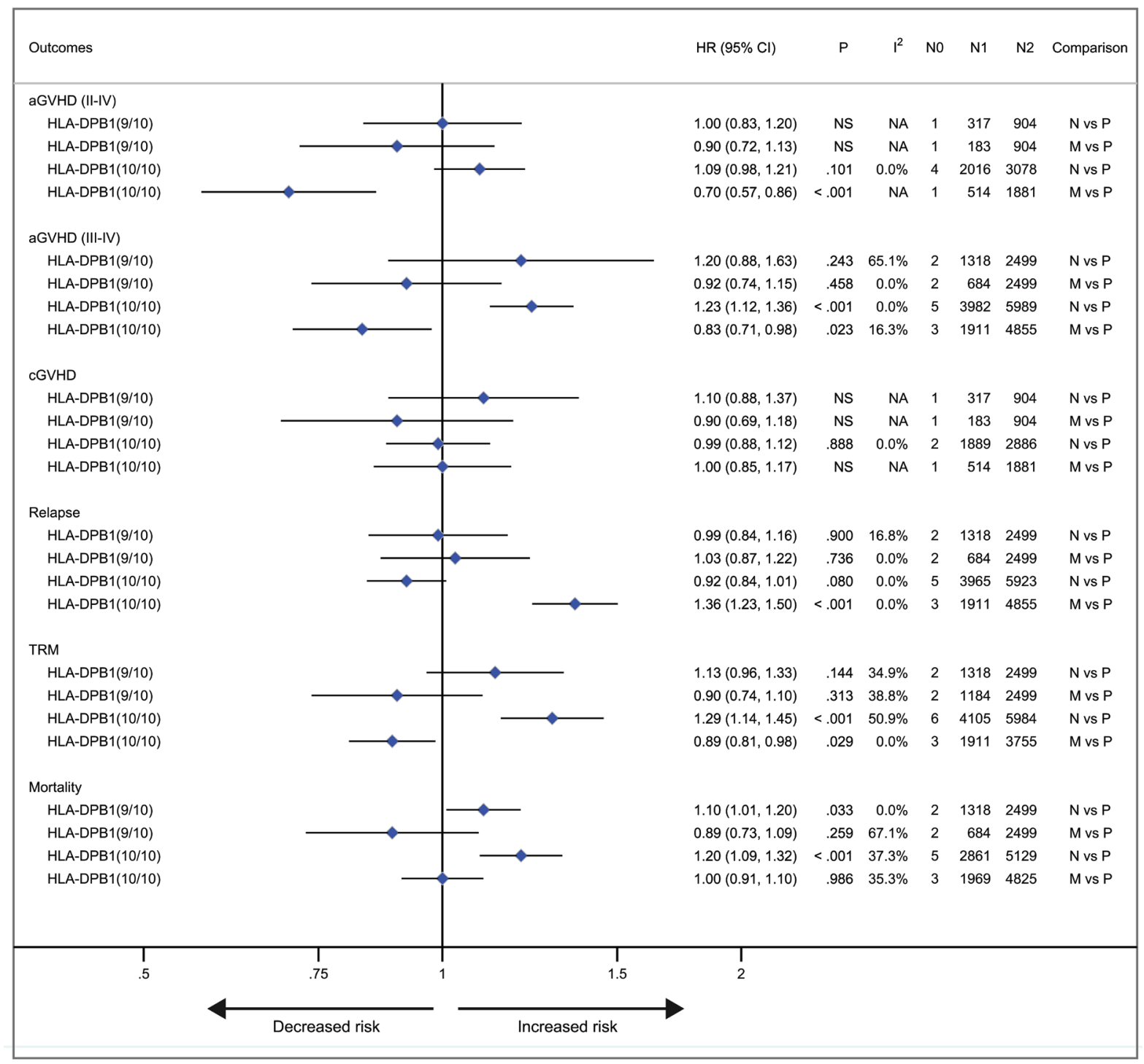

Figure 4: Nonpermissive mismatched or matched HLA-DPB1 alleles versus permissive mismatched HLA-DPB1 alleles. Pooled hazard ratios (HRs) and $95 \%$ CIs for post-transplantation end points. N0, number of studies; N1, number of patients as the case; N2, number of patients as the control. 9/10, comparisons in the population with 9/10 HLA matching; 10/10, comparisons in the population with 10/10 HLA matching. $\mathrm{N}$ vs $\mathrm{P}$, nonpermissive mismatch versus permissive mismatch; $\mathrm{M}$ vs $\mathrm{P}$, match versus permissive mismatch. NS, not significant; NA, not available. 


\section{DISCUSSION}

\section{Summary main results}

We found HLA-DQB1 locus mismatches had no significant impact on multiple outcomes except for TRM, it is a potential candidate of permissive HLA locus mismatches. Secondly, we attempted to identify several candidates serving as remarkable graft-versustumor effects (GVT). HLA-DPB1 locus mismatches had a significantly protective effect against leukemia relapse, which was attributed to nonpermissive HLA-DPB1 mismatches. Meanwhile, mismatched HLA-DPB1 had no significant impact on chronic GVHD, TRM or mortality. But relative to permissive mismatches, nonpermissive HLA-DPB1 mismatches had a significantly increased risk of TRM and mortality in 10/10 HLA matching. Similarly, HLA-C locus mismatches had a trend of reduced risk of relapse, but had a significant increased risk of TRM and mortality and a slightly increased risk of chronic GVHD. Thirdly, mismatches at HLA-A, -B, -DRB1 loci significantly increased the risks of acute GVHD, TRM and

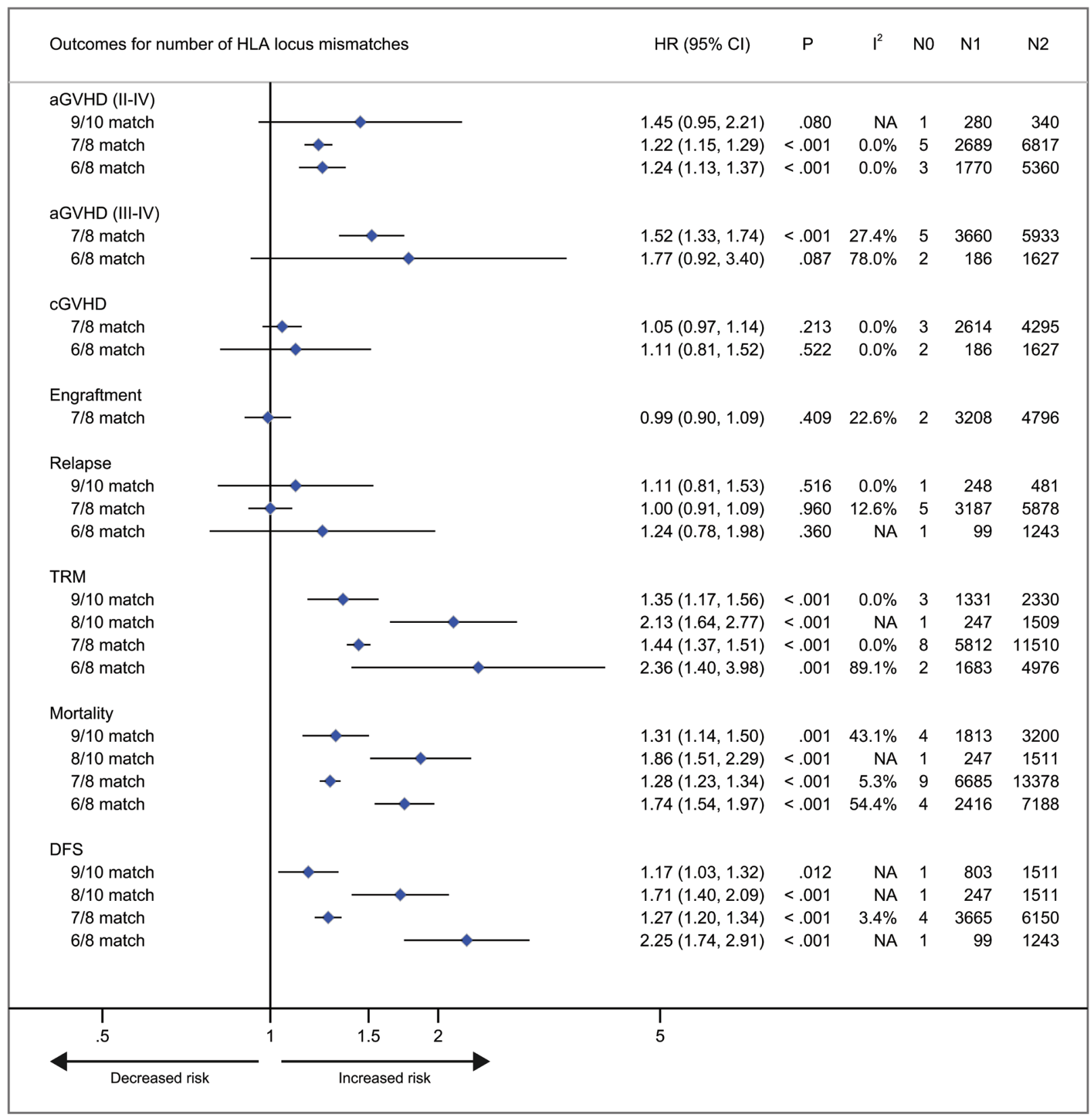

Figure 5: Number of HLA locus mismatches. Pooled hazard ratios (HRs) and 95\% CIs for post-transplantation end points. 7/8 or 6/8 HLA matching versus 8/8 HLA matching; 9/10 or 8/10 HLA matching versus 10/10 HLA matching. N0, number of studies; N1, number of patients as the case; N2, number of patients as the control; NA, not available. 
mortality, but had no significant protection against primary disease relapse.

\section{Agreements and disagreements with other studies}

Most recently, one meta-analysis demonstrated that 9/10 HLA matching had a higher risk of mortality, compared with $10 / 10$ matching, with hazard ratio of 1.27 (95\% CI, 1.12 to $1.45 ; P<.001)$ [56], which was similar to ours (HR, $1.31 ; 95 \% \mathrm{CI}, 1.14$ to $1.50 ; P=.001)$. In addition, the risk for individual HLA allele mismatches was similar with it in our stratified analyses. However, multiple comparisons for other important outcomes were not performed in the pool-analysis. Many low-quality studies with small sample size were included, which did not meet our eligible criteria. To our knowledge, our metaanalysis is the first to systematically and comprehensively assess the impact of HLA locus mismatches on clinical outcomes in unrelated donor HCT.

\section{Strengths and limitations of this study}

Our meta-analysis had several strengths. Firstly, a large number of patients were included to obtain a bigger statistical power for a given comparison. Secondly, a series of end points were assessed in an effort to obtain a comprehensive recognition about the effect of individual HLA locus mismatches. Thirdly, the risk of individual HLA locus mismatches was similar among analogous end points, which contributed to the robustness of pooled estimates. For instance, mismatches at HLA-DQB1 locus had no impact on both acute GVHD (II-IV) and acute GVHD (III-IV). Furthermore, HLA-DQB1 locus mismatches were better tolerated than other HLA loci for acute GVHD. In terms of TRM, the pooled point estimates of class I HLA molecules were greater than those of class II HLA molecules, as observed for mortality. Fourthly, given the highest mismatched likelihood of HLA-DPB1 alleles, we explored the impact of nonpermissive HLADPB1 locus mismatches on multiple end points. Fifthly, we assessed the impact of number mismatches of HLA loci on outcomes. Sixthly, Donor-recipient baseline characteristics were summarized together in order to demonstrate the practical application field of pooled results.

There were several limitations in our meta-analysis. First of all, all of our main pooled estimates belonged to average effects for individual HLA loci, with combining results from different studies presented separately as 1 allele mismatching, 1 or 2 allele mismatching or a single mismatching. Few studies investigated the effect of 2 antigen mismatches at individual HLA loci [38]. Second, clinical heterogeneity from individual studies such as donor age, patients' performance status, primary disease, disease status at HCT, intensity of conditioning regimen and GVHD prophylaxis, grafts with $\mathrm{T}$ cell depletion, were difficult to be completely balanced between cases and controls, especially in studies with relatively small sample size [17, 20, 22, 32, 45]. Third, bone marrow transplantation reduced the risk of chronic GVHD but increase the risk of graft failure, compared with peripheral blood transplantation [57, 58]. In our study, $69.9 \%$ patients received bone marrow derived hematopoietic cells, which might attenuate the risk of individual HLA locus mismatches for chronic GVHD and neutrophil engraftment. Similarly, the inclusion of anti-thymocyte globulin (ATG) into conditioning regimen for patients with leukemia resulted in significantly decreased risk of chronic GVHD after allogeneic transplantation [59, 60], but the effect of HLA locus mismatching was not analyzed according to the application of ATG in included studies. Fourth, with respect to the same primary disease, the therapy strategy has been evolving over time, which might decrease the incidence of complications [17, 61]. Fifth, HLA genes match likelihood at high resolution varied across different race and ethnicity groups [62], detailed information was not presented in many studies. Sixth, HLA locus mismatching had a higher risk of mortality in recipients with standard-risk disease compared those with high-risk disease [19, 27]. In our meta-analysis, less than half of the population was standard-risk disease status at HCT. Seventh, significant heterogeneity mainly existed in the mismatches at the HLA-A, -C and -DPB1 loci. We conducted a sensitivity analysis to figure out the robustness of pooled results. As shown in Supplementary Figure S1, using the trim and fill method, the robustness of all of the pooled estimates were presented in both fixed and random-effects models [55]. It is notable that HLA-C locus mismatches had a significantly reduced risk of relapse compared with matched control $(P<.001$ and $P=.017$ respectively). We stratified the HLA-C locus mismatches into three groups: 1 allele, 1 antigen and 1 or 2 allele mismatches, the hazard ratios of relapse were 0.88 (95\% CI, 0.70 to $\left.1.10 ; P=.259 ; \mathrm{I}^{2}=33.7 \%\right), 1.04$ ( $95 \% \mathrm{CI}, 0.91$ to $\left.1.20 ; P=.531 ; \mathrm{I}^{2}=0.0 \%\right)$ and $0.70(95 \%$ CI, 0.62 to $0.79 ; P<.001 ; \mathrm{I}^{2}=0.0 \%$ ), respectively. The heterogeneity appeared to be found, but results of the subgroups were less robust for fewer studies used in each pooled analysis. To explore the heterogeneity of HLADPB1 mismatches for acute GVHD (II-IV), we excluded 2 studies with small sample size and 1 study with GVH direction mismatches, and then pooled the remaining results, with hazard ratio of 1.34 (95\% CI, 1.27 to 1.42 ; $P<.001 ; \mathrm{I}^{2}=0.0 \%$ ), which was consistent with it from the primary analysis. We failed to reveal possible sources of heterogeneity for TRM at HLA-DPB1 locus, and for chronic GVHD and acute GVHD (III-IV) at HLA-C locus. Eighth, we were unable to assess publication bias because of relatively few studies for most of the end points. Ninth, specific HLA genotype mismatching combination among donor-recipient pairs was investigated in few studies, the 
pool-analysis could not be performed [31, 43]. Last but not least, in the absence of more detailed information, predefined subgroup analyses could not be conducted.

\section{Assessment of HLA locus mismatches in terms of expression levels or amino acid substitutions}

Most recent studies attempted to identify permissive mismatches in terms of expression levels of HLA-C and -DPB1 $[63,64]$. With respect to HLA-C molecule, patients with higher expression of mismatched HLA-C tended to suffer from higher risk of actue GVHD (IIIIV) and nonrelapse mortality compared with those with lower expression mismatches. Furthermore, the definitive correlation of most HLA-C allotypes with their corresponding expression levels will be beneficial to the selection of permissive mismatched donors in terms of HLA genotype. A similar finding was identified in HLA-DPB1 mismatches. When donors with lowexpression HLA-DPB1 molecules, recipients with mismatched high-expression HLA-DPB1 had a higher risk of acute GVHD (II-IV), compared with patients with low-expression HLA-DPB1 mismatches. It is found that high-expression HLA-DPB1 correlated with its singlenucleotide variant (rs9277534G) of the sixth exon in the 3' untranslated region. In contrast, HLA-DPB1 expression was lower when with the rs9277534A variant. A possible explanation is that non-coding RNA might mediate the HLA-DPB1 RNA silencing through binding rs9277534A. In addition, some studies attempted to identify specific nonpermissive HLA locus mismatches according to amino acid substitutions (AAS) at key peptide-binding residues of HLA molecules. For example, among the population with a single HLA-C mismatches, ASS at position 116 had a significantly increased risk of acute GVHD (III-IV), compared with those without the AAS [65].

\section{MATERIALS AND METHODS}

This meta-analysis is reported according to the PRISMA statement [66]

\section{Eligibility criteria}

Studies should be included when meeting the following criteria: (1) patients receiving unrelated-donor HCT; (2) patients with hematological disorders; (3) high-resolution typing was performed as described for HLA-A, -B, -C, -DRB1, -DQB1, and/or -DPB1 loci; (4) investigating the impact of HLA locus mismatching on clinical outcomes; (5) cohort studies. If a study meet any of the following criteria, it should be excluded: (1) HLA locus mismatch combinations; (2) analysis of HLA protein expression; (3) mismatched HLA alleles as controls except for HLA-DPB1; (4) data presented as percentage; (5) unrelated versus related donor HCT; (6) meeting abstract or case report.

\section{Study searching and selection}

We searched four databases (PubMed, Embase, Web of Science and the Cochrane Library) from inception to February 2016, with these keyword combinations involving "hematopoietic", "hematologic" or "transplantation"; "unrelated"; "human leukocyte antigen" or "major histocompatibility complex"; and "mismatch" or "mismatched". The complete search strategy is available in the appendix (Supplementary Table 1). Two reviewers (R.T. and T.Z.) independently selected studies based on the eligibility criteria. Disagreements were resolved through discussing with a third reviewer (B.Y.).

\section{Definition of end points}

Primary end points included grade II to IV aGVHD, grade III to IV aGVHD, chronic GVHD (cGVHD), neutrophil engraftment and disease relapse. The incidence of grades II-IV or III-IV acute GVHD was defined according to the Glucksberg scale [67]. Chronic GVHD included limited and extensive conditions and was defined according to the Seattle criteria [68]. Neutrophil engraftment was defined achieving an absolute neutrophil count $>0.5 \times 10^{9} / \mathrm{L}$ for 3 consecutive days after transplantation. Relapse was regarded as recurrence of primary leukemia or myelodysplastic syndrome (MDS). Secondary end points were as follows: transplant-related mortality (TRM), Mortality and disease-free survival (DFS). Overall mortality was defined as time from HCT to death from any cause. TRM was death without evidence of primary disease recurrence after HCT. DFS was defined as time to relapse of primary disease or death from any cause.

\section{Risk of bias within and across studies}

Risk of bias within studies was assessed independently by the two authors (R.T. and T.Z.) using the Newcastle-Ottawa Scale (NOS) components for cohort studies [69]. Studies were scored to be low risk of bias $(\geq$ 3 points) or higher risk of bias ( $<3$ points). Disagreement was resolved through discussing with a third author (B.Y.). Publication bias was not investigated, because of less than 10 studies included for most of the end points.

\section{HLA typing}

In our meta-analysis, high-resolution HLA typing refers to obtaining diversity of the allele sequence at individual HLA loci for donor-recipient pairs, using various methods such as sequencing based 
typing [70], sequence specific priming [71], reference strand conformation analysis [72], sequence specific oligonucleotide probing [73] and so on. Low-resolution HLA (antigen or serologic level) disparities are derived from converting high-resolution typing to its corresponding serologic equivalents, except for a few HLA-B alleles mapping to their specific equivalents [74].

\section{HLA matching}

Whenever assessing the effect of individual HLA locus mismatches, we predefined controls as patients with corresponding HLA allele matching adjusted with other HLA allele matching, or those with complete HLA allele matching. Individual HLA locus mismatches involved allele-level (1 or 2 alleles), antigen-level (1 or 2 antigens) and/or a single (1 allele or 1 antigen) mismatches, as presented in studies. Secondly, there were at most 6 HLA loci (HLA-A, HLA-B, HLA-C, HLA-DRB1, HLA-DQB1 and HLA-DPB1) investigated in some studies. Highresolution matching at 5 loci (except for HLA-DPB1) is designated as 10/10 HLA matching, HLA 9/10 matching refers to donor-recipient pairs with a single mismatches at any one of the 5 loci, HLA 8/10 matching includes two allele or antigen mismatches at one or two of the 5 HLA loci; and high-resolution matching at 4 loci (except for HLA-DPB1 and HLA-DQB1) is designated as 8/8 HLA matching, HLA 7/8 matching was defined as donorrecipient pairs with a single mismatches at any one of the 4 loci, HLA 6/8 matching includes two mismatch (allele or antigen) at one or two of the 4 HLA loci. Additionally, in a population with HLA-DPB1 allele mismatches, permissive HLA-DPB1 mismatches are T-cell-epitope group matches, whereas nonpermissive HLA-DPB1 mismatches belong to T-cell-epitope group mismatches in either graft-versushost or host-versus-graft direction [30, 35, 42].

\section{Data extraction}

Data were extracted as follows: (1) the baseline characteristics of donor-recipient pairs and individual studies; (2) data presented as multivariate-adjusted point estimates and corresponding 95\% CIs for each comparison. Among the included studies, some data were showed as HR, others were presented as relative risk (RR) or odds ratio (OR). We uniformed effect measure as HR in our meta-analysis. Two reviewers (R.T. and T.Z.) independently extracted these data using a spreadsheet developed specifically for the meta-analysis. Discrepancies were resolved through discussing with a third reviewer (B.Y.).

\section{Data synthesis and analysis}

Primary analyses compared mismatches at individual HLA loci with corresponding controls. Separately, we assessed the impact of nonpermissive mismatches and matches at HLA-DPB1 locus on multiple end points, as compared to permissive HLA-DPB1 mismatches. Secondary analyses evaluated the impact of number of HLA locus mismatches on multiple end points. In addition, we summarized the baseline characteristics of included studies and patients separately, and calculated the matching likelihood of individual HLA loci based on a larger population. We pooled HRs and $95 \%$ CIs using the Mantel-Haneszel random-effects model for each comparison $[75,76]$. The magnitude of between-studies heterogeneity was assessed using the $\mathrm{I}^{2}$ statistic, with value $\geq 50 \%$ indicating substantial heterogeneity, $\mathrm{I}^{2}$ value $<50 \%$ was not showed in the text [77-79].

\section{Sensitivity and subgroup analyses}

Firstly, with respect to pooled estimates with a substantial heterogeneity, we performed a sensitivity analysis using the trim and fill adjustment method (random and fixed effects linear estimator) in an effort to investigate the robustness of primary synthesized results [80]. Secondly, we did stratified analysis according to mismatched level (allele and/or antigen) at individual HLA loci. Additional subgroups analyses should be performed according to the quality of studies, direction of HLA locus mismatching, patient or donor age, disease status before HCT, intensity of conditioning regimen, grafts with T-cell depletion, GVHD treatment, cytomegalovirus serostatus of donor-recipient pairs, duration of follow up.

All statistical tests were 2 -sided, $P$ value $<.05$ was considered statistically significant. The meta-analysis was performed using STATA/SE version 12.0.

\section{CONCLUSIONS}

We identify HLA-DQB1 locus mismatches as a permissive mismatching, which offers HCT choices for patients without all 5 HLA-locus matched grafts. HLA-DPB1 locus nonpermissive mismatches have a significantly protective effect against leukemia relapse, simultaneously have no significantly increased risk of TRM, mortality or DFS. HLA-C locus mismatches have a trend of protecting against leukemia relapse. Further researches should be conducted to confirm our findings using individual patient data meta-analysis, and should assess the impacts of individual HLA locus mismatches on multiple outcomes in terms of the allele and antigen levels respectively. Subgroup analysis should be performed according to disease category, disease status at HCT, intensity of conditioning regimen, T-cell depletion or 
not, and so on. More studies are needed to identify and verify permissive mismatches at HLA-C and DPB1 loci in unrelated donor HCT.

\section{GRANT SUPPORT}

This work was supported by the National Natural Science Foundation of China (Grant No. 81471582, No. 81370647 and No. 81520108002$)$.

\section{CONFLICTS OF INTEREST}

The authors declare no competing financial interests.

\section{REFERENCES}

1. Hansen JA, Clift RA, Thomas ED, Bucker CD, Storb R and Giblett ER. Transplantation of marrow from an unrelated donor to a patient with acute leukemia. N Engl J Med. 1980; 303:565-567.

2. Gratwohl A, Pasquini MC, Aljurf M, Atsuta Y, Baldomero H, Foeken L, Gratwohl M, Bouzas LF, Confer D, Frauendorfer K, Gluckman E, Greinix H, Horowitz M, et al. One million haemopoietic stem-cell transplants: a retrospective observational study. The Lancet Haematology. 2015; 2:e91-e100.

3. Michonneau D, Sagoo P, Breart B, Garcia Z, Celli S and Bousso P. The PD-1 axis enforces an anatomical segregation of CTL activity that creates tumor niches after allogeneic hematopoietic stem cell transplantation. Immunity. 2016; 44:143-154.

4. Wingard JR, Majhail NS, Brazauskas R, Wang Z, Sobocinski KA, Jacobsohn D, Sorror ML, Horowitz MM, Bolwell B, Rizzo JD and Socie G. Long-term survival and late deaths after allogeneic hematopoietic cell transplantation. J Clin Oncol. 2011; 29:2230-2239.

5. Pasquini M, Wang Z, Horowitz MM and Gale RP. 2013 report from the Center for International Blood and Marrow Transplant Research (CIBMTR): current uses and outcomes of hematopoietic cell transplants for blood and bone marrow disorders. Clinical transplants. 2013; 8:187-197.

6. Pagano L, Caira M, Nosari A, Van Lint MT, Candoni A, Offidani M, Aloisi T, Irrera G, Bonini A, Picardi M, Caramatti C, Invernizzi R, Mattei D, et al. Fungal infections in recipients of hematopoietic stem cell transplants: results of the SEIFEM B-2004 study--Sorveglianza Epidemiologica Infezioni Fungine Nelle Emopatie Maligne. Clin Infect Dis. 2007; 45:1161-1170.

7. Boeckh M. The challenge of respiratory virus infections in hematopoietic cell transplant recipients. Br J Haematol. 2008; 143:455-467.

8. Styczynski J, Tridello G, Gil L, Ljungman P, Hoek J, Iacobelli S, Ward KN, Cordonnier C, Einsele H, Socie G, Milpied N, Veelken H, Chevallier P, et al. Impact of donor epstein-barr virus serostatus on the incidence of graft-versus-host disease in patients with acute leukemia after hematopoietic stem-cell transplantation: a study From the Acute Leukemia and Infectious Diseases Working Parties of the European Society for Blood and Marrow Transplantation. J Clin Oncol. 2016; 66:1-9.

9. Valcarcel D, Martino R, Caballero D, Martin J, Ferra C, Nieto JB, Sampol A, Bernal MT, Pinana JL, Vazquez L, Ribera JM, Besalduch J, Moraleda JM, et al. Sustained remissions of high-risk acute myeloid leukemia and myelodysplastic syndrome after reduced-intensity conditioning allogeneic hematopoietic transplantation: chronic graft-versus-host disease is the strongest factor improving survival. J Clin Oncol. 2008; 26:577-584.

10. Bornhäuser $\mathrm{M}$, Kienast $\mathrm{J}$, Trenschel R, Burchert A, Hegenbart U, Stadler M, Baurmann H, Schäfer-Eckart K, Holler E, Kröger N, Schmid C, Einsele H, Kiehl MG, et al. Reduced-intensity conditioning versus standard conditioning before allogeneic haemopoietic cell transplantation in patients with acute myeloid leukaemia in first complete remission: a prospective, open-label randomised phase 3 trial. The Lancet Oncology. 2012; 13:1035-1044.

11. Devine SM, Owzar K, Blum W, Mulkey F, Stone RM, Hsu JW, Champlin RE, Chen YB, Vij R, Slack J, Soiffer RJ, Larson RA, Shea TC, et al. Phase II study of allogeneic transplantation for older patients with acute myeloid leukemia in first complete remission using a reducedintensity conditioning regimen: results from Cancer and Leukemia Group B 100103 (Alliance for Clinical Trials in Oncology)/Blood and Marrow Transplant Clinical Trial Network 0502. J Clin Oncol. 2015; 33:4167-4175.

12. Jodele S, Licht C, Goebel J, Dixon BP, Zhang K, Sivakumaran TA, Davies SM, Pluthero FG, Lu L and Laskin BL. Abnormalities in the alternative pathway of complement in children with hematopoietic stem cell transplant-associated thrombotic microangiopathy. Blood. 2013; 122:2003-2007.

13. Ruutu T, Barosi G, Benjamin RJ, Clark RE and George JN. Diagnostic criteria for hematopoietic stem cell transplantassociated microangiopathy: results of a consensus process by an International Working Group. Hematologica. 2007; 92:95-100.

14. Jodele S, Zhang K, Zou F, Laskin B, Dandoy CE, Myers KC, Lane A, Meller J, Medvedovic M, Chen J and Davies $\mathrm{SM}$. The genetic fingerprint of susceptibility for transplantassociated thrombotic microangiopathy. Blood. 2016; 127:989-996.

15. Warren EH, Zhang XC, Li S, Fan W, Storer BE, Chien JW, Boeckh MJ, Zhao LP, Martin PJ and Hansen JA. Effect of $\mathrm{MHC}$ and non-MHC donor/recipient genetic disparity on the outcome of allogeneic HCT. Blood. 2012; 120:27962806.

16. Morishima Y, Sasazuki T, Inoko H, Juji T, Akaza T and Yamamoto K. The clinical significance of human leukocyte 
antigen (HLA) allele compatibility in patients receiving a marrow transplant from serologically HLA-A, HLA-B, and HLA-DR matched unrelated donors. Blood. 2002; 99:42004206.

17. Zino E, Frumento G, Marktel S, Sormani MP, Ficara F, Terlizzi SD, Parodi AM, Sergeant R, Martinetti M, Bontadini A, Bonifazi F, Lisini D, Mazzi B, et al. A T-cell epitope encoded by a subset of HLA-DPB1 alleles determines nonpermissive mismatches for hematologic stem cell transplantation. Blood. 2004; 103:1417-1424.

18. Flomenberg N, Baxter-Lowe LA, Confer D, FernandezVina M, Filipovich A, Horowitz M, Hurley C, Kollman C, Anasetti C, Noreen H, Begovich A, Hildebrand W, Petersdorf E, et al. Impact of HLA class I and class II highresolution matching on outcomes of unrelated donor bone marrow transplantation: HLA-C mismatching is associated with a strong adverse effect on transplantation outcome. Blood. 2004; 104:1923-1930.

19. Petersdorf EW, Anasetti C, Martin PJ, Gooley T, Radich J, Malkki M, Woolfrey A, Smith A, Mickelson E and Hansen JA. Limits of HLA mismatching in unrelated hematopoietic cell transplantation. Blood. 2004; 104:2976-2980.

20. Tiercy JM, Passweg J, Biezen A, Zander A, Kroger N, Gratwohl A, Chapuis B, Helg C, Brinch L, Cornelissen J, Oudshoorn M, Ruutu T, Volin L, et al. Isolated HLA-C mismatches in unrelated donor transplantation for CML. Bone Marrow Transplant. 2004; 34:249-255.

21. Chalandon Y, Tiercy JM, Schanz U, Gungor T, Seger R, Halter J, Helg C, Chapuis B, Gratwohl A, Tichelli A, Nicoloso de Faveri G, Roosnek E, Passweg JR, et al. Impact of high-resolution matching in allogeneic unrelated donor stem cell transplantation in Switzerland. Bone Marrow Transplant. 2006; 37:909-916.

22. Ho VT, Kim HT, Liney D, Milford E, Gribben J, Cutler C, Lee SJ, Antin JH, Soiffer RJ and Alyea EP. HLA-C mismatch is associated with inferior survival after unrelated donor non-myeloablative hematopoietic stem cell transplantation. Bone Marrow Transplant. 2006; 37:845850 .

23. Shaw BE, Marsh SG, Mayor NP, Russell NH and Madrigal JA. HLA-DPB1 matching status has significant implications for recipients of unrelated donor stem cell transplants. Blood. 2006; 107:1220-1226.

24. Shaw BE, Gooley TA, Malkki M, Madrigal JA, Begovich AB, Horowitz MM, Gratwohl A, Ringdén O, Marsh SGE and Petersdorf E. The importance of HLA-DPB1 in unrelated donor hematopoietic cell transplantation. Blood. 2007; 110:4560-4566.

25. Lee SJ, Klein J, Haagenson M, Baxter-Lowe LA, Confer DL, Eapen M, Fernandez-Vina M, Flomenberg N, Horowitz M, Hurley CK, Noreen H, Oudshoorn M, Petersdorf E, et al. High-resolution donor-recipient HLA matching contributes to the success of unrelated donor marrow transplantation. Blood. 2007; 110:4576-4583.

26. Morishima Y, Yabe T, Matsuo K, Kashiwase K, Inoko H,
Saji H, Yamamoto K, Maruya E, Akatsuka Y, Onizuka M, Sakamaki H, Sao H, Ogawa S, et al. Effects of HLA allele and killer immunoglobulin-like receptor ligand matching on clinical outcome in leukemia patients undergoing transplantation with T-cell-replete marrow from an unrelated donor. Biol Blood Marrow Transplant. 2007; 13:315-328.

27. Petersdorf EW, Gooley T, Malkki M and Horowitz M. Clinical significance of donor-recipient HLA matching on survival after myeloablative hematopoietic cell transplantation from unrelated donors. Tissue Antigens. 2007; 69:25-30.

28. Ludajic K, Balavarca Y, Bickeboller H, Pohlreich D, Kouba M, Dobrovolna M, Vrana M, Rosenmayr A, Fischer GF, Fae I, Kalhs P and Greinix HT. Impact of HLA-DPB1 allelic and single amino acid mismatches on HSCT. Br J Haematol. 2008; 142:436-443.

29. Crocchiolo R, Ciceri F, Fleischhauer K, Oneto R, Bruno B, Pollichieni S, Sacchi N, Sormani MP, Fanin R, Bandini G, Bonifazi F, Bosi A, Rambaldi A, et al. HLA matching affects clinical outcome of adult patients undergoing haematopoietic SCT from unrelated donors: a study from the Gruppo Italiano Trapianto di Midollo Osseo and Italian Bone Marrow Donor Registry. Bone Marrow Transplant. 2009; 44:571-577.

30. Crocchiolo R, Zino E, Vago L, Oneto R, Bruno B, Pollichieni S, Sacchi N, Sormani MP, Marcon J, Lamparelli T, Fanin R, Garbarino L, Miotti V, et al. Nonpermissive HLA-DPB1 disparity is a significant independent risk factor for mortality after unrelated hematopoietic stem cell transplantation. Blood. 2009; 114:1437-1444.

31. Kawase T, Matsuo K, Kashiwase K, Inoko H, Saji H, Ogawa S, Kato S, Sasazuki T, Kodera Y and Morishima Y. HLA mismatch combinations associated with decreased risk of relapse: implications for the molecular mechanism. Blood. 2009; 113:2851-2858.

32. Park M, Koh KN, Kim BE, Im HJ, Park KD, Kang HJ, Shin HY, Ahn HS, Yoo KH, Sung KW, Koo HH, Park HJ, Park $\mathrm{BK}$, et al. The impact of HLA matching on unrelated donor hematopoietic stem cell transplantation in Korean children. Korean J Hematol. 2011; 46:11-17.

33. Woolfrey A, Klein JP, Haagenson M, Spellman S, Petersdorf E, Oudshoorn M, Gajewski J, Hale GA, Horan J, Battiwalla M, Marino SR, Setterholm M, Ringden O, et al. HLA-C antigen mismatch is associated with worse outcome in unrelated donor peripheral blood stem cell transplantation. Biol Blood Marrow Transplant. 2011; 17:885-892.

34. Horan J, Wang T, Haagenson M, Spellman SR, Dehn J, Eapen M, Frangoul H, Gupta V, Hale GA, Hurley CK, Marino S, Oudshoorn M, Reddy V, et al. Evaluation of HLA matching in unrelated hematopoietic stem cell transplantation for nonmalignant disorders. Blood. 2012; 120:2918-2924.

35. Fleischhauer K, Shaw BE, Gooley T, Malkki M, Bardy P, 
Bignon JD, Dubois V and Horowitz MM. Effect of T-cellepitope matching at HLA-DPB1 in recipients of unrelateddonor haemopoietic-cell transplantation: a retrospective study. The Lancet Oncology. 2012; 13:366-374.

36. Saber W, Opie S, Rizzo JD, Zhang MJ, Horowitz MM and Schriber J. Outcomes after matched unrelated donor versus identical sibling hematopoietic cell transplantation in adults with acute myelogenous leukemia. Blood. 2012; 119:39083916.

37. Wang $\mathrm{TF}$, Huang $\mathrm{H}$, Tzeng $\mathrm{CH}$, Wang $\mathrm{PN}, \mathrm{Wu} \mathrm{T}$, Sun J, Tang JL, Hu J, Lin SF and Kao RH. Impact of donor characteristics and HLA matching on survival of chinese patients with hematologic malignancies undergoing unrelated hematopoietic stem cell transplantation. Biol Blood Marrow Transplant. 2012; 18:1939-1944.

38. Fürst D, Müller C, Vucinic V, Bunjes D, Herr W and Gramatzki M. High-resolution HLA matching in hematopoietic stem cell transplantation: a retrospective collaborative analysis. Blood. 2013; 122:3220-3229.

39. Hurley CK, Woolfrey A, Wang T, Haagenson M, Umejiego J, Aljurf M, Askar M, Battiwalla M, Dehn J, Horan J, Oudshoorn M, Pidala J, Saber W, Turner V, et al. The impact of HLA unidirectional mismatches on the outcome of myeloablative hematopoietic stem cell transplantation with unrelated donors. Blood. 2013; 121:4800-4806.

40. Kanda Y, Kanda J, Atsuta Y, Maeda Y, Ichinohe T, Ohashi K, Fukuda T, Miyamura K, Iida H, Mori T, Iwato K, Eto $\mathrm{T}$, Kawa $\mathrm{K}$, et al. Impact of a single human leucocyte antigen (HLA) allele mismatch on the outcome of unrelated bone marrow transplantation over two time periods. A retrospective analysis of 3003 patients from the HLA Working Group of the Japan Society for Blood and Marrow Transplantation. Br J Haematol. 2013; 161:566-577.

41. Saber W, Cutler CS, Nakamura R, Zhang MJ, Atallah E, Rizzo JD, Maziarz RT, Cortes J, Kalaycio ME and Horowitz MM. Impact of donor source on hematopoietic cell transplantation outcomes for patients with myelodysplastic syndromes (MDS). Blood. 2013; 122:1974-1982.

42. Fleischhauer K, Fernandez-Vina MA, Wang T, Haagenson M, Battiwalla M, Baxter-Lowe LA, Ciceri F, Dehn J, Gajewski J, Hale GA, Heemskerk MB, Marino SR, et al. Risk associations between HLA-DPB1 T-cell epitope matching and outcome of unrelated hematopoietic cell transplantation are independent of HLA-DPA1. Bone Marrow Transplant. 2014; 49:1176-1183.

43. Fernandez-Viña MA, Wang T, Lee SJ, Haagenson M and Aljurf M. Identification of a permissible HLA mismatch in hematopoietic stem cell transplantation. Blood. 2014; 123:1270-1278.

44. Pidala J, Lee SJ, Ahn KW, Spellman S and Wang HL. Nonpermissive HLA-DPB1 mismatch increases mortality after myeloablative unrelated allogeneic hematopoietic cell transplantation. Blood. 2014; 124:2596-2606.

45. Thus KA, Ruizendaal MT, de Hoop TA, Borst E, van Deutekom HW, Te Boome L, Kuball J and Spierings E.
Refinement of the definition of permissible HLA-DPB1 mismatches with predicted indirectly recognizable HLADPB1 epitopes. Biol Blood Marrow Transplant. 2014; 20 :1705-1710.

46. Gagne K, Loiseau P, Dubois V, Dufosse F, Perrier P, Dormoy A, Jollet I, Renac V, Masson D, Picard C, Lafarge $\mathrm{X}$, Hanau D, Quainon F, et al. Is there any impact of HLA-DPB1 disparity in 10/10 HLA-matched unrelated hematopoietic SCT? Results of a French multicentric retrospective study. Bone Marrow Transplant. 2015; 50:232-236.

47. Sato-Otsubo A, Nannya Y, Kashiwase K, Onizuka M, Azuma F, Akatsuka Y, Ogino Y, Satake M, Sanada M, Chiba S, Saji H, Inoko H, Kennedy GC, et al. Genome-wide surveillance of mismatched alleles for graft-versus-host disease in stem cell transplantation. Blood. 2015; 126:27522763.

48. Kanda J, Ichinohe T, Fuji S, Maeda Y, Ohashi K, Fukuda T, Miyamura K, Iwato K, Eto T, Nakamae, H, Kobayashi N, Mori T, Mori S, et al. Impact of HLA mismatch direction on the outcome of unrelated bone marrow transplantation: a retrospective analysis from the Japan Society for Hematopoietic Cell Transplantation. Biol Blood Marrow Transplant. 2015; 21:305-311.

49. Verneris MR, Lee SJ, Ahn KW, Wang HL, Battiwalla M, Inamoto Y, Fernandez-Vina MA, Gajewski J, Pidala J, Munker R, Aljurf M, Saber W, Spellman S, et al. HLA mismatch is associated with worse outcomes after unrelated donor reduced-intensity conditioning hematopoietic cell transplantation: an analysis from the center for international blood and marrow transplant research. Biol Blood Marrow Transplant. 2015; 21:1783-1789.

50. Morishima Y, Kashiwase K, Matsuo K, Azuma F, Morishima $\mathrm{S}$ and Onizuka M. Biological significance of HLA locus matching in unrelated donor bone marrow transplantation. Blood. 2015; 125:1189-1197.

51. Kollman C, Spellman SR, Zhang MJ, Hassebroek A and Anasetti C. The effect of donor characteristics on survival after unrelated donor transplantation for hematologic malignancy. Blood. 2016; 127:260-267.

52. Hurley CK, Baxter Lowe LA, Logan B, Karanes C and Anasetti C. National marrow donor program HLA-matching guidelines for unrelated marrow transplants. Biol Blood Marrow Transplant. 2003; 9:610-615.

53. Bray RA, Hurley CK, Kamani NR, Woolfrey A, Müller C, Spellman S, Setterholm M and Confer DL. National marrow donor program HLA matching guidelines for unrelated adult donor hematopoietic cell transplants. Biol Blood Marrow Transplant. 2008; 14:45-53.

54. Spellman SR, Eapen M, Logan BR, Mueller C, Rubinstein P, Setterholm MI, Woolfrey AE, Horowitz MM, Confer DL and Hurley CK. A perspective on the selection of unrelated donors and cord blood units for transplantation. Blood. 2012; 120:259-265.

55. Howard CA, Fernandez-Vina MA, Appelbaum FR, Confer 
DL, Devine SM, Horowitz MM, Mendizabal A, Laport GG, Pasquini MC and Spellman SR. Recommendations for donor human leukocyte antigen assessment and matching for allogeneic stem cell transplantation: consensus opinion of the blood and marrow transplant clinical trials network (BMT CTN). Biol Blood Marrow Transplant. 2015; 21:4-7.

56. Kekre N, Mak KS, Stopsack KH, Binder M, Ishii K, Branvall E and Cutler CS. Impact of HLA-mismatch in unrelated donor hematopoietic stem cell transplantation: a meta-analysis. Am J Hematol. 2016; 91:551-555.

57. Eapen M, Rocha V, Sanz G, Scaradavou A, Zhang MJ, Arcese W, Sirvent A and Champlin RE. Effect of graft source on unrelated donor haemopoietic stemcell transplantation in adults with acute leukaemia: a retrospective analysis. The Lancet Oncology. 2010; 11:653660.

58. Anasetti C, Logan BR, Lee SJ, Waller EK, Weisdorf DJ, Wingard JR, Cutler CS, Westervelt P, Woolfrey A, Couban S, Ehninger G, Johnston L, Maziarz RT, et al. Peripheralblood stem cells versus bone marrow from unrelated donors. N Engl J Med. 2012; 367:1487-1496.

59. Kroger N, Solano C, Wolschke C, Bandini G, Patriarca F, Pini M, Nagler A, Selleri C, Risitano A, Messina G, Bethge W, Duarte R, Carella AM, et al. Antilymphocyte globulin for prevention of chronic graft-versus-host disease. N Engl J Med. 2016; 374:43-53.

60. Walker I, Panzarella T, Couban S, Couture F, Devins G, Elemary M, Gallagher G, Kerr H, Kuruvilla J, Lee SJ, Moore J, Nevill T, Popradi G, et al. Pretreatment with antithymocyte globulin versus no anti-thymocyte globulin in patients with haematological malignancies undergoing haemopoietic cell transplantation from unrelated donors: a randomised, controlled, open-label, phase 3, multicentre trial. The Lancet Oncology. 2016; 17:164-173.

61. Gooley TA, Chien JW, Pergam SA, Hingorani S, Sorror ML, Boeckh M, Martin PJ and Sandmaier BM. Reduced mortality after allogeneic hematopoietic-cell transplantation. N Engl J Med. 2010; 363:2901-2101.

62. Gragert L, Eapen M, Williams E, Freeman J, Spellman S, Baitty R, Hartzman R, Rizzo JD, Horowitz M, Confer D and Maiers M. HLA match likelihoods for hematopoietic stem-cell grafts in the U.S. registry. N Engl J Med. 2014; 371:339-348.

63. Petersdorf EW, Gooley TA, Malkki M, Bacigalupo AP, Cesbron A, Toit ED and Ehninger G. HLA-C expression levels define permissible mismatches in hematopoietic cell transplantation. Blood. 2014; 124:3996-4003.

64. Petersdorf EW, Malkki M, O'HUigin C, Carrington M, Gooley T, Haagenson MD, Horowitz MM, Spellman SR, Wang T and Stevenson P. High HLA-DP expression and graft-versus-host disease. N Engl J Med. 2015; 373:599609.

65. Pidala J, Wang T, Haagenson M, Spellman SR, Askar M, Battiwalla $\mathrm{M}$ and Baxter-Lowe LA. Amino acid substitution at peptide-binding pockets of HLA class I molecules increases risk of severe acute GVHD and mortality. Blood. 2013; 122:3651-3658.

66. Liberati A, Altman DG, Tetzlaff J, Mulrow C, Gotzsche PC, Ioannidis JP, Clarke M, Devereaux PJ, Kleijnen J and Moher D. The PRISMA statement for reporting systematic reviews and meta-analyses of studies that evaluate health care interventions: explanation and elaboration. PLoS Med. $2009 ; 6: 1-28$.

67. Glucksberg H, Storb R, Fefer A, Buckner CD, Neiman PE, Clift RA, Lerner $\mathrm{KG}$ and Thomas ED. Clincal manifestations of graft-versus-host disease in human recipients of marrow from HLA-matched slibling donors. Transplantation. 1974; 18:295-304.

68. Shulman HM, Sullivan KM, Weiden PL, Mcdonald GB and Sale GE. Chronic graft-versus-host syndrome in man. a long-term clinicopathologic study of 20 seattle patients. The American Journal of Medicine. 1980; 69:204-217.

69. Stang A. Critical evaluation of the Newcastle-Ottawa scale for the assessment of the quality of nonrandomized studies in meta-analyses. Eur J Epidemiol. 2010; 25:603-605.

70. Pera C, Delfino L, Morabito A, Longo A, Johnston-Dow L, White CB, Colonna M and Ferrara GB. HLA-A typing: comparison between serology, the amplification refractory mutation system with polymerase chain reaction and sequencing. Tissue Antigens. 1997; 50:372-379.

71. Olerup $\mathrm{O}$ and Zetterquist H. HLA-DR typing by PCR amplification with sequencespecific primers (PCR-SSP) in 2 hours: An alternative to serological DR typing in clinical practice including donor-recipient matching in cadaveric transplantation. Tissue Antigens. 1992; 39:225-235.

72. Arguello JR, Little AM, Bohan E, Goldman JM, Marsh SGE and Madrigal JA. High resolution HLA class I typing by reference strand mediated conformation analysis (RSCA). Tissue Antigens. 1998; 52:57-66.

73. Date Y, Kimura A, Kato H and Sasazuki T. DNA typing of the HLA-A gene: population study and identification of four new alleles in Japanese. Tissue Antigens. 1996; 47:93-101.

74. Schreuder GM, Hurley CK, Marsh SG, Lau M, Maiers M, Kollman C and Noreen HJ. The HLA Dictionary 2001: a summary of HLA-A, -B, -C, -DRB1/3/4/5, -DQB1 alleles and their association with serologically defined HLA-A, -B, -C, -DR and -DQ antigens. Tissue Antigens. 2001; 58:109140.

75. DerSimonian R and Laird N. Meta-Analysis in Clinical Trials. Controlled Clinical Trial. 1986; 7:177-188.

76. DerSimonian R and Kacker R. Random-effects model for meta-analysis of clinical trials: an update. Contemp Clin Trials. 2007; 28:105-114.

77. Higgins JP and Thompson SG. Quantifying heterogeneity in a meta-analysis. Stat Med. 2002; 21:1539-1558.

78. Higgins JP, Thompson SG, Deeks JJ and Altman DG. Measuring inconsistency in meta-analyses. BMJ. 2003; 327:557-560.

79. Crippa A, Khudyakov P, Wang M, Orsini N and Spiegelman 
D. A new measure of between-studies heterogeneity in meta-analysis. Stat Med. 2016.

80. Peters JL, Sutton AJ, Jones DR, Abrams KR and Rushton
L. Performance of the trim and fill method in the presence of publication bias and between-study heterogeneity. Stat Med. 2007; 26:4544-4562. 